\title{
Cloud Computing for Solving E-Learning Problems
}

\author{
N. S. Abu El-Ala \\ Elec. \& Comm. Dept.; Industrial Technical Institute; \\ Port-Said Technological College; Egypt
}

\author{
W. A. Awad \\ Math. \& Comp. Dept.; Faculty of Science; \\ Port Said University; Egypt
}

\author{
H. M. El-Bakry \\ Inf. Systems Dept; \\ Faculty of Computer and Information Sciences; \\ Mansoura University; Egypt
}

\begin{abstract}
The integration of information and communication technologies in education according to the global trend occupied a great interest in the Arab world through E-Learning techniques and put it into the form of services within Services Oriented Architecture Technique (SOA), and mixing its input and outputs within the components of the Education Business Intelligence (EBI) and enhance it to simulate reality by educational virtual worlds. This paper presents a creative environment derived from both virtual and personal learning environments based on cloud computing which contains variety of tools and techniques to enhance the educational process. The proposed environment focuses on designing and monitoring educational environment based on reusing the existing web tools, techniques, and services to provide Browser-based-Application.
\end{abstract}

\section{INTRODUCTION}

There is much debate among those interested in education and E-Learning in the Arab world about the advantages and disadvantages of this system of education, and most Arabic academic conference papers presented concerned completely with the same topic which is the advantages and disadvantages and the comparison with the traditional educational systems, so in this paper we will move from E-Learning evaluation to fly in the space of implementation.

The problem is no longer to prove the importance of ELearning but it is to switch to E-Learning, most educational institutions collide the barrier of foundation when they plan to move to E-Learning systems which require many hardware and software resources.

The educational cloud provides a magic solution to this problem where any educational institution wants to transform its system to E-Learning system. It will have two choices whether to build its own private cloud or to go to a specific service provider to share in a pubic cloud after defining some parameters.

All the users need a host in a data center somewhere in the world, or even multiple data centers scattered around the world, and cloud computing providers deliver common applications online that are accessed from web browsers, also can provide a storage unit to store all learners documents.
No one can ignore that both web 2.0 technologies have changed the nature of the internet from a place to read static pages to an environment that allows end-users to access applications using web browser without purchasing licenses or upgrade hardware, where all software and files hosted in the cloud and accessed by wide range of hardware devices such as mobile phones, computers or PDAs while the internet connection is available.

The following sections focus on how to use cloud computing to enhance the education process specifically in the Arab world. The first section Addresses cloud computing concept and its features, the second section addresses ELearning environment based on cloud, and the third section compares between existing sites to enhance the existing Arabic E-Learning sites.

\section{Cloud COMPUTING.}

No one can deny the vital role that cloud plays in developing educational systems recently, but until now there isn't a specific definition for cloud computing.

Simply cloud computing provides anytime / anywhere services that can be accessed from any device in such a way that user is not responsible for where the services or applications are located or how it maintained or updated, all this and more will be the responsibility of cloud computing service providers such as Google and Amazon EC2, etc...

Cloud computing not only saves the money needed for upgrading many labs' hardware or purchase many software licenses but also it relieves the user from periodic maintenance operations. It also provides a high level of security and privacy.

But before transforming your E-Learning system to the cloud, you should identify which services you need and create a service catalogue (list of services you will provide to learners who will access your site) to determine the parameters you will need from service provider, also it will help you whenever you need to update your system. Recent research papers categorize the cloud services into two basic branches as following: 


\section{A. IT Services.}

It includes all the services related to the infrastructure of the cloud such as physical resources (as storage devices, school servers, and national communication network, etc), and virtual resources that concern with the management and the access of the physical resources.

\section{B. User Services.}

It can be divided into two types, generic services (as EMail, search, portal, and social networking) and Education services (as e-portfolio, content access and creation).

After determining the required services which serve the curriculum requirements provided by the institution to the students and teachers, a service level agreement will be established between the institution and cloud provider to define the parameters the institution needs.

\section{1) E-Learning Environments.}

There are many different educational environments that serve the educational process based on computer and its technologies. For example Web 2.0 technologies which provide teachers with new ways to engage students, and help student to participate on a global level by using the network as a platform for information sharing, interoperability, user-centered design and collaboration on the World Wide Web.

A Web 2.0 site allows users to interact and collaborate with one another in a social media dialogue as creators of usergenerated content in a virtual community, which helped the appearance of learning environments such as virtual learning environment and personal learning environment. Before proposing a framework for E-Learning environment with the aid of cloud computing technology, let's know more about the pervious environments.

\section{a) Virtual Learning Environment (VLE):}

It is a set of teaching and learning tools designed to enhance a student's learning experience by including computers and the Internet in the learning process where included web-based access to class content, grades, assessments, and other class tools. It is also a social space where students and teacher can interact through threaded discussions or chat.

It also includes students and teacher "meeting" online through a synchronous web-based application. The teacher is able to present lessons through video, PowerPoint, or chatting. The students are able to talk with other students and the teacher, as well as collaborate with one another, answer questions, or pose questions. They can use the available tools through the application to virtually raise their hands, send messages, or answer questions on the screen given by the teacher.

\section{b) Personal Learning Environment (PLE):}

The expression does not refer to a specific service or application but rather to an idea of how learners achieve their learning goals. PLE provides learners with support in managing their content and communication with peers in the process of learning by dividing them into groups for discussions, providing context, and il $\neg$ lustrating processes.
PLE provides a suitable environment to practice social skills. There are many types of PLEs that are classified based on their architecture such as PLEX or web-based with loosely joined web services such as ELGG or are classified based on their platform like facebook. Another approach of PLEs is based on their pedagogical approach that serves formal and informal learning process.

\section{c) Mash-up Personal Learning Environments (MUPPLE):}

This environment is a mixing between the previous environments where they allow learners to build their own personal learning environment by composing web-based tools, get involved in collaborative activities, share their designs with peers, and adapt their designs to reflect their experience in the learning process.

After identifying the E-Learning environments and recognizing the features of each environment, we will move to the following section which is concerned with the outline a framework for E-Learning environment with aid of cloud technology as shown in Fig.1.

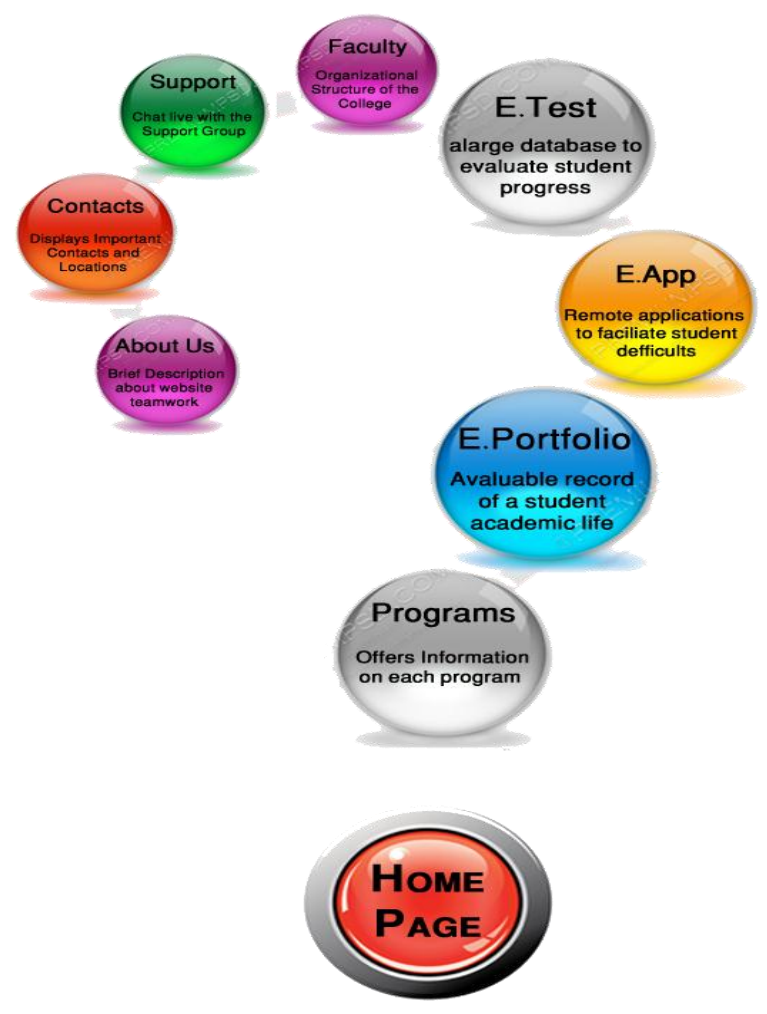

Fig.1 E-Learning Framework

\section{2) Cloud-based E-Learning System.}

This section concerns with designing web-based ELearning system that contains various social tools, smart agents and interactive environment of web 2 techniques uploaded to cloud as shown in Fig. 2. The system has three major parts. The first part addresses the web-based Course Management System (CMS) which is managed by the web server to register learner to access course materials that are provided and maintained by teachers. 
The second part is a PLE which provide various tools and services to help learners in building their own environment. The third part addresses building an online virtual computing lab as shown in Fig. 3, Fig. 1 Site Map. providing a remote access service that allows the leaner to reserve a computer with a desired set of applications such as Photoshop, Packet Tracer, AutoCAD, and many others Linux and numerous windows environments and remotely access it over high-speed internet connection.

All of this and more shown through an attractive easy-touse interface represented in a OnTheWay web interface which achieves a set of criteria to facilitate the students' tasks.

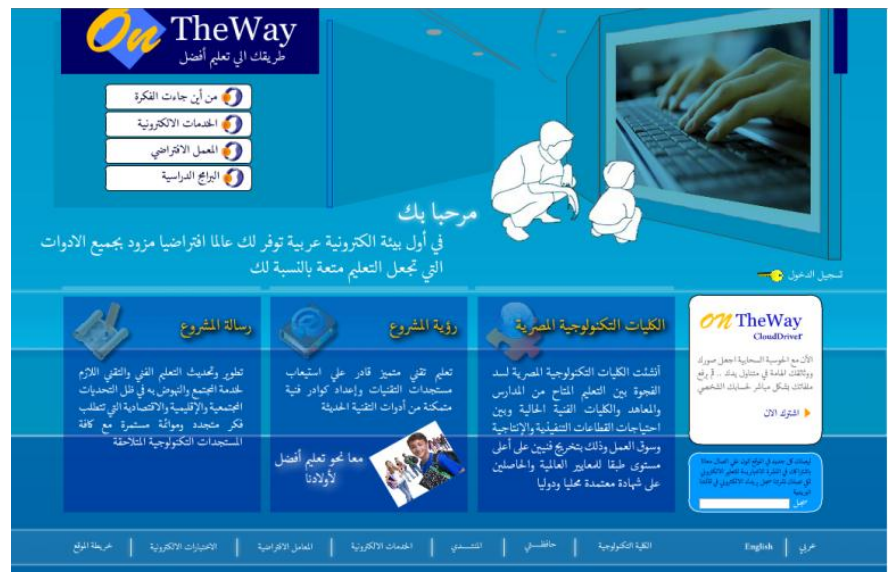

Fig. 2 OnTheWay Web Site, Homepage.

- OnTheWay achieves the learning objectives accredited curriculum department of the Ministry of Higher Education and teacher-defined course goals.

- OnTheWay provides the means to deliver high quality digital learning applications fully integrated into any course. Learners learn by access text and multimedia content.

- OnTheWay provides both teachers and learners the ability and storage area to upload all their documents, projects, homework and photos at their fingertips.

- OnTheWay provides the technology, tools and professional development that facilitate the students' task and help them to share and present their ideas, thinking and learning by using OnTheWay forums.

- OnTheWay provides the technology, tools that helps students to access their virtual computing lab to implement their educational activities by providing a number of Windows and Linux environments and set of suggested programs.

- OnTheWay provides the students with online test which provide various questions on various topics to improve the students' skills.

- OnTheWay provides learners the ability to follow up their performance level by assignment report, progress report, working portfolios, and projects Evaluation.

The user interface is friendly, and accessible.

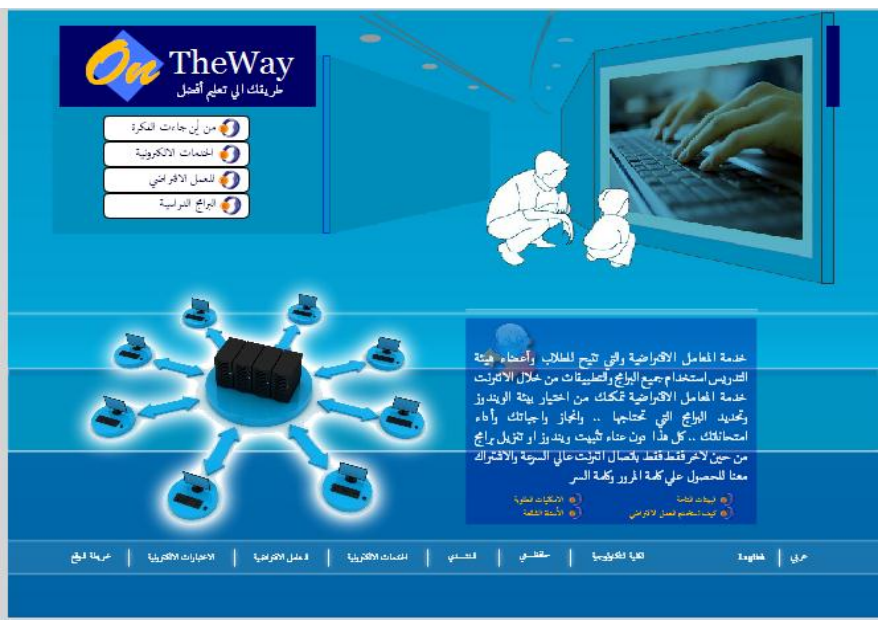

Fig. 3 OnTheWay Web Site, Virtual Computing Lab (VCL) Page.

\section{CONCLUSION}

In this paper we tried to prove that cloud computing changed E-Learning future systems. A wide world of knowledge and tools now is available to Arabic teachers and learners through cloud based services all the time and accessed from anywhere, from any device.

\section{REFERENCE:}

[1] .Paul POCATILU; "Cloud Computing Benefits for E-Learning Solutions"; Economics of Knowledge; Vol. 2; Issue 1; 1Q 2010; pp. 914.

[2] DeCoufle B.; "The Impact of Cloud Computing in Schools"; The Datacenter Journal; http://datacenterjournal.com/content/view/3032/40/; July 2009.

[3] Pocatilu P., Boja C.; " Quality Characteristics and Metrics related to MLearning Process"; Amfiteatru Economic; Year XI; No. 26; June 2009.

[4] Pocatilu P., Boja C.; "Cloud Computing Incidents Database"; wiki.cloudcommunity.org/wiki; 2010.

[5] Cena F. Farzan R. Lops P.; "Web 3.0: Merging Semantic Web with Social Web"; Proceedings of the 20th ACM conference on Hyper-text and hypermedia; HT'09; June 29- 1 July; 2009.

[6] Mohammed Al-Zoube; "E-Learning on the Cloud"; International Arab Journal of E-Technology; Vol. 1; No. 2; June 2009.

[7] WHITE PAPER, Intel ${ }^{\circledR}$ World Ahead Cloud Computing; "The Education Cloud: Delivering Education as a Service"; 2010.

[8] http://www.educause.edu/eli; EDUCAUSE Learning Initiative; advancing learning through it innovation ; "7 things you should know about.. Personal Learning Environments"; May 2009.

[9] Fridolin Wild, Felix Mödritscher and Steinn Sigurdarson; "Designing for Change: Mash-Up Personal Learning Environments"; www.elearningpapers.eu; July 2008.

[10] http://www.fullerton.edu/VCL/ index.asp; July 2012.

[11] http://www.vcl.ncsu.edu/; May2012. 